\section{Advances in Fungal Biotechnology}

Ed: Rai, M, 2009. pp 545, Hard Cover, I.K. International Publishing House Pvt. Ltd. New Delhi, India

ISBN 9 78-81-89866-53-2, Price INR 1995.00

Plant Biology teaching programmes in most of the universities, both technical and traditional ones, include a course in "economic botany". But it largely includes only crops, trees, some medicinal herbs and shrubs. Pitifully, these courses rarely include the economic wealth of fungi, algae or other important microflora and plants that are of rich therapeutic and economic value. An important reason for this ignorance and/or negligence, among others, is the lack of good and affordable text books and reference books providing adequate coverage to these organisms at a level suitable for undergraduate, graduate and post graduate students.

Therefore, the book "Advances in Fungal Biotechnology" edited by Mahendra Rai is a pleasant welcome and a timely addition to this rapidly growing field in plant science. The book contains 19 chapters contributed by 38 experts from Brazil, Canada, India, Nigeria, Portugal, Poland, Spain, USA and UK. The editor, a Professor of Biotechnology at Amaravati University, Maharashtra, India, must be complemented for putting together authoritative overviews on a broad spectrum of fungal and yeast biotechnologies in this book.

The articles can be broadly divided into three groups. The first group includes topics such as 'weed control' by fungi (Chapter 1), fungal resistant crops (Chapter 2), pathogenic fungi (Chapter 3), fungal community structure with reference to DGGE, TGGE (Chapter 16); fungi for indoor environments (Chapter 15), causal fungal organisms, prognosis and therapy (Chapter 17) and also a chapter on health implications, antifungal drugs and mycotoxins relating to chronic toxigenic mold exposure (Chapter 18). These six chapters comprehensively discuss the theme from biology to technology and economics.

The second group deals with technological and commercial prospective of enzymes from fungi like xylanse (Chapter 4), laccase (Chapter 5), fungal pigments for industry (Chapter 7) and an exhaustive overview on mushrooms as sources of enzymes (Chapter 6). This section also includes an interesting essay on microbial transformation using Beauveria bassiana (Chapter 8) as well as on biotransformation of terpenes by fungi (Chapter 9). These chapters will be of use for experts as well as non-initiated researchers, as the technological perspectives are in abundance.

The third group contains topics such as value-added citric acid (Chapter 11) and vitamin (Chapter 14) production by fungi, arbuscular mycorrhizal fungi for revegetation (Chapter 12) and Ectomycorrhizal fungi for forest nursery use (Chapter
13). These chapters highlight the promise of fungi in industry, agriculture, horticulture, forestry and landscaping. There is also a referral essay on "Mycology on the Internet "(Chapter 19) that is of significant interest for those seeking additional resources, considering that internet has become a global resource of information.

Finally, the book provides glimpses into yeast biotechnology with its vast and robust potential for therapeutic and commercial applications, through an interesting essay on the design of yeast strains for glucose/ lactose metabolism (Chapter 10) using Kluveromyces and Saccharomyces. Though this chapter is well discussed, some recent aspects of candida yeast biology would have been welcome to underscore the importance of fungal diversity in biotechnology.

In summary, the book contains an assortment of topics that provide current progress and advances on fungal physiology, biochemistry and biotechnology. However, the chapters are a bit patchy and disjuncted. Chapters written by diverse groups are expected to be inherently non-uniform, but the editor has to strive to make it cohesive and reader friendly. A summary to each chapter would have been of help to prime the general readers, as well as to provide a take home lesson.

Nevertheless, given the intricacies of fungal diversity and their ecological, agricultural, medicinal and industrial uses, the editor Prof. Mahendra Rai ought to be complemented for his bold efforts. The authors and publishers must also be complemented for bringing out an excellent hard bound book replete with figures, graphs, tables, formulae and a rich source of recent references. The expert and the novice would enjoy it equally and benefit from the new insights it offers across many areas of biotechnology. Unlike many other scientific and technical books, this book is very affordable for students and teachers. The quality of production by IK International measures up to the reputation of a high ranking publisher.

This book is highly recommended for graduate courses and research students in biotechnology, pharmacy, plant biology and agriculture/forestry programmes. It must be made available in colleges, universities, research institutes and departmental libraries.

Prasanna Mohanty Formerly Professor Photo-biochemistry and Bioenergetics Jawahar Nehru University, New Delhi Professor (Honorary) of Functional Ecology, Regional Plant Resource Centre, Bhubaneswar, and Courtesy - Professor of Life Sciences at DAVV, Indore, India E-mail : photosis@rediffmail.com 